Running head: THE PSYCHOLOGY OF TRAIT ANGER

The Facts on the Furious:

\title{
A Brief Review of the Psychology of Trait Anger
}

\author{
Lotte Veenstra ${ }^{\mathrm{a}}$
}

Brad J. Bushman a,b

Sander L. Koole 


\begin{abstract}
Some people are more prone to aggression than others. These individual differences are associated with trait anger, a personality dimension that relates to the frequency, intensity, and duration with which people experience angry feelings. Trait anger is an important antecedent of state anger and aggression. People with high trait anger tend to perceive situations as hostile and are less capable of controlling their hostile thoughts and feelings. M oreover, people with high trait anger display heightened approach motivation in threatening situations. This reactive approach motivation may be countered by avoidance states, which may reduce anger among high trait-anger people. Insights into the underlying processes of trait anger may be used to combat human aggression.
\end{abstract}

Key words: trait anger; state anger; aggression; cognitive control; approach and avoidance motivation; emotion regulation; situated social cognition 


\section{TheFacts on theFurious: A Brief Review of the Psychology of TraitAnger}

Human aggression is any behavior directed toward another person that is carried out with the immediate intent to cause harm [1]. A ggression is inherent in human nature. War and bloodshed have been pervasive throughout history [2] and virtually everyone has hurt someone physically or psychologically, or at least felt like doing so. N evertheless, some people have more aggressive inclinations than others. These individual differences are associated with trait anger, or the frequency, duration, and intensity with which people become angry [3-5]. In this article, we briefly review recent advances in the psychology of trait anger. We begin by characterizing trait anger as a personality disposition and its role in people's emotional lives. N ext, we discuss research on the underlying cognitive and motivational mechanisms of trait anger. Finally, we consider how the resulting insights may be used to combat aggression in everyday life.

\section{Trait Anger as a Personality Disposition}

Individual differences in how easily people become angry have been observed at least since ancient Greeks (around 400 BCE ), who noted that people with a choleric temperament are aggressive, ego-centric, quickly aroused, restless, and impulsive $[6,7]$. These descriptions have striking resemblance with modern conceptions of trait anger. Scientific research on trait anger started during the 1950s, when psychologists first became interested in individual differences in anger $[8,9]$. Building on this early work, Charles Spielberger and his associates introduced their influential state-trait personality theory of anger in the 1980s [10],*[11]. In this theoretical conception, state anger is an acute emotional-physiological reaction that ranges from mild irritation to intense fury and rage. Trait anger, by contrast, is a personality dimension that reflects the person's chronic tendency to experience the emotion of state anger with greater frequency, intensity, and duration. Conceptualizing trait anger as an individual- 
difference variable implies that, across a variety of situations, people high on trait anger will become angry more often, more intensely, and for longer periods of time than people low on trait anger.

To measure trait anger, Spielberger and associates devel oped the trait anger scale of the State-Trait-A nger Inventory (STA XI) [10], *[11] in which people rate how they generally feel on brief, face-valid items such as "I feel infuriated when I do a good job and get a poor evaluation" or "W hen I get frustrated, I feel like hitting someone". Similar self-report measures have been developed by other researchers [12,13]. Although the various scales differ in some respects, they probably measure the same underlying construct [14]. We therefore refer to all relevant individual difference measures as simply 'trait anger'. For ease of presentation, we often discuss trait anger by referring to people on opposite ends of the trait anger continuum (e.g., 'people high versus low in trait anger'). However, this is a simplification, so it should be kept in mind that people actually vary in trait anger in a continuous, graded manner.

Trait anger consistently predicts state anger and aggressive behavior in everyday life. For instance, people high (rather than low) on trait anger report feeling more anger while driving, along with more aggressive driving behavior, and they are involved in more driving accidents *[15]. Likewise, employees high (rather than low) on trait anger report experiencing angry feelings more often at the workplace [16]. Finally, a meta analytic review of 85 studies showed that men high on trait anger are more likely to physically abuse their female partners than men low on trait anger [17]. Thus, people high on trait anger may even direct their anger and aggression towards their loved ones.

In the aforementioned studies, people were asked to think back about their daily lives, which may introduce memory bias. This problem is alleviated when researchers use 
experience sampling, a methodology in which people record their responses while they are immersed in their daily activities, often using mobile technology such as cell phones [18], *[19]. One such study asked 165 A merican university employees to report their anger every 25-30 minutes over two days, separated by a period of 6 months [20]. Trait like stability betw een everyday responses of anger on numerous occasions and a variety of contexts was very high, such that reported anger for one day related highly with reported anger several months later. These individual differences were associated with trait anger, though the strength of this relationship was modest. M ore work is needed to develop individual differences measures of trait anger that go beyond self-report, for instance, by using implicit measures such as increased attention towards aggressive cues [21], or physiological measures [22].

\section{TraitAnger as a Cognitive Disposition}

Researchers have conducted laboratory studies of trait anger, which offer more control over the kinds of circumstances to which people are exposed, and allow researchers to examine causal mechanisms. For instance, one innovative study examined drivers with varying levels of trait anger during a driving simulation [23]. Consistent with field observations *[15], high trait-anger drivers drove faster, had more accidents, higher arousal, and scored higher in state anger compared with low trait-anger drivers. Other laboratory studies have shown that imagining anger-provoking situations leads people with high (rather than low) trait anger to display greater increases in cardiovascular arousal, and feelings of anger, but no greater increases in other emotions such as fear or joy $[24,25]$.

To explain the behavioral and emotional effects of trait anger, many researchers have suggested that trait anger is related to systematic biases in processing information $[1,5,26,27]$. Indeed, several studies have shown that high trait anger is associated with selective attention 
to hostile social cues such as aggressive action words (e.g., kick, assault, punch) [21], autobiographical memories of the self as an angry person [28], rumination about angerprovoking experiences [29], and the tendency to interpret the behavior of others in a hostile manner [30]. For example, people with high (rather than low) trait anger tend to explain ambiguous situations with derogatory descriptions such as "the person in the story isn't smart enough, was feeling angry, and will storm out of the room" [30].

Trait anger is further associated with impaired mobilization of effortful control, especially in anger-relevant situations [9]. For instance, compared with people with low trait anger, people with high trait anger tend to make more errors when they have to inhibit their response while viewing angry faces, but not while viewing happy faces [31]. The idea that effortful control is important to anger regulation meshes well with the broader emotion regulation literature, which suggests that effortful control is vital for gaining mastery over one's emotional life [32]. Lapses in effortful control may disrupt the ability of high trait anger people to reappraise the situation in less hostile terms, to distract themselves from hostile contextual cues, and to suppress aggressive impulses once these are triggered.

\section{Trait Anger as a Motivational Disposition}

Over the past decades, the biological foundations of trait anger have become increasingly clear. B ehavior-genetic analyses indicate that anger displays during childhood are moderately to highly heritable [33,34]. The specific genes that regulate anger and aggression have remained el usive [34]. Still, there is ample evidence that individual differences in anger are at least partly biologically based. The neurophysiological system that is most implicated in trait anger is the approach system [35]. This motivational system provides the impulse to go tow ard $* *[36]$. The approach system competes with the avoidance system, which provides the motivational impulse to go away. B oth the approach system and 
the avoidance system belong to a deep biological heritage, which presides in rudimentary form in all life forms that have had to fight or flee for their survival [37].

Several lines of research have found that high trait anger is associated with selfreported, neurological, and physiological indicators of approach motivation. In self-report measures, for instance, higher levels of trait anger have been found to be associated with increased reward sensitivity, an indicator of the approach system [38]. On a neurological level, higher trait anger is associated with more activation in the left anterior cortex [39], which is involved in approach behavior [40]. Finally, on a physiological level, higher levels of trait anger are associated with approach-related neuro-endocrine responses such as increases in testosterone [41], and increased cardiovascular activity in response to challenges and stress, which may contribute to high blood pressure and cardiovascular disease [22].

If approach motivation drives the behavioral effects of trait anger, then trait anger should be linked to increases in approach motivation in anger-relevant situations. Several studies have indeed observed this pattern of reactive approach motivation among people with high trait anger. For instance, painful noise blasts lead people with high (rather than) low trait anger to more strongly favor maximizing rewards at the expense of minimizing threats [42]. Likewise, people with high (rather than) low trait anger respond with greater approachrelated neural activations to pictures related to anger, but not to pictures related to fear or disgust [39]. Finally, people with high (rather than) low trait anger are faster to make approach (rather than) avoidance movements, but only when responding to angry faces with a direct eye gaze, not when responding to smiling faces or angry faces with an averted eye gaze, which are not overtly threatening *[43]. These and related findings suggest that the link between trait anger and approach motivation becomes potentiated in socially threatening situations. 
If reactive increases in approach motivation lead people high in trait anger to become angry and aggressive, then lowering approach motivation - for instance by activating avoidance tendencies - may down-regulate state anger and aggression among people with high trait anger. Indeed, some recent studies showed that avoidance cues such as leaning back (instead of leaning forward) or pushing away (instead of pulling toward) can down-regulate anger and aggression among people with high trait anger [44]. These findings confirm that reactive approach motivation plays a causal role in the heightened anger and aggression that is displayed by high trait anger people.

\section{Condusions and Outlook}

In recent years, scientists have made considerable advances in unraveling the psychology of trait anger. A visual summary of the major research findings on trait anger is provided by Figure 1. Self-report measures of trait anger predict situational angry feelings and aggression in both everyday life and well-controlled laboratory studies. Trait anger has been linked to cognitive biases, such as reduced capacity for effortful control, which lead high trait anger people to quickly perceive their surroundings as hostile. Finally, high trait anger is linked to increased approach motivation, especially in threatening situations.

So far, the cognitive and motivational processes associated with trait anger have been investigated independently. How ever, the distinction between motivation and cognition is somew hat artificial, given that motivation and cognition are known to interact continuously [45]. Such motivation-cognition interactions are likely to be important in trait anger. Indeed, ground-breaking studies have shown that anger-related approach motivation leads to perceptional and conceptual narrowing of attention *[46]. M ore research along these lines will be needed to unravel the interplay of motivation and cognition in trait anger. 
Insights into the basic processes that underlie trait anger may be utilized to improve the effectiveness of anger management interventions. Problems with anger management are common in many psychological disorders*[47][4]. Traditional cognitive interventions such as cognitive behavior therapy (CBT) can be effective [48,49]. However, people with anger issues often show low treatment readiness, al ong with alarmingly high drop-out rates during interventions [50]. It thus seems important to consider al ternative interventions. For instance, there is preliminary evidence that training avoidance tendencies towards threatening situations may improve anger management among people with high trait anger *[51][52]

We opened this article with the rather pessimistic observation that aggression is inherent to human nature. This is not to say, however, that aggression is inevitable. Historical records indicate that aggressive behavior has steadily decreased over the millennia [2]. Efforts to further reduce human aggression may capitalize on the growing scientific insights regarding individual differences in trait anger. As the cognitive and motivational mechanisms of trait anger become increasingly understood, practitioners will become better equipped to develop more targeted interventions. This may help angry people who would otherwise resort to aggression to maintain more peaceful relations with others. 


\section{R eferences and recommended reading}

Papers of particular interest, published within the period of review, have been highlighted as:

* of special interest

** of outstanding interest

* [11] C.D. Spielberger, E .C . R eheiser, A ssessment of emotions: Anxiety, anger, depression, and curiosity, A ppl. Psychol. Heal. Well-Being. 1 (2009) 271-302. doi: 10.1111/j.1758-0854.2009.01017.x.

Charles Spielberger, one of the main pioneers in trait anger research, outlines the historical background related to theory and research on anger as emotion and personality trait. A fter fourty years of research with state-trait inventories for anger anxiety, depression, and curiosity, Spielberger underlines the importance of measuring state- as well as trait-related emotional experiences, to better diagnose and treat psychological illness.

* [15] J .L . D effenbacher, A.N. Stephens, M.J .M. Sullman, Driving anger as a psychological construct: Twenty years of research using the Driving Anger Scale, Transp. Res. Part F. 42 (2016) 236-247. doi:10.1016/j.trf.2015.10.021.

The authors review an extensive research program into trait driving anger. Trait driving anger partly overlaps with the more general personality disposition of trait anger, but the two constructs are empirically separable. The authors discuss the negative social impacts of trait driving anger, such as the aggressive driving behaviors that cause accidents and car crashes in everyday life.

** [19]R .A. Sherman, J .F. R authmann, N A. Brown, D.G . Serfass, A .B . J ones, The independent effects of personality and situations on real-time expressions of behavior and emotion, J. Pers. Soc. Psychol. 109 (2015) 872-888. doi: 10.1037/ pspp0000036. 
A ground-breaking experience sampling study on trait anger, which shows how daily behavior and emotions predict personality traits and situation characteristics independently. The authors discuss the consequences of the absence of an interaction between personality and situation for the most important traditional personality theories.

\section{** [36]E . H armon-J ones, C. Harmon-J ones, T.F. Price, W hat is approach motivation?, E mot. Rev. 5 (2013) 291-295. doi:10.1177/1754073913477509.}

Concise review on approach motivation and its role in emotional processing and anger. The authors integrate knowledge from animal and human research to show how approach motivation functions to direct our behavior to go toward a stimulus, regardless of its positive or negative valence.

\section{* [43] L. Veenstra, I.K . Schneider, B J . B ushman, S.L. K oole, Drawn to danger: trait anger predicts automatic approach behaviour to angry faces., Cogn. E mot. 9931 (2016) 1-7. doi:10.1080/02699931.2016.1150256.}

A $n$ experimental study that demonstrates the situated nature of the link between trait anger and approach motivation. Specifically, high trait anger predicted relatively faster approach than avoidance movements towards angry faces. This effect did not occur for angry faces with an averted eye gaze, or happy faces, presumably because they did not pose a specific social threat.

\section{* [46] P.A. Gable, B.D. Poole, E. Harmon-J ones, Anger perceptually and conceptually narrows cognitive scope., J . Pers. Soc. Psychol. 109 (2015) 163-174. doi:10.1037/ a0039226.}

This paper reports a provocative set of studies that illuminate the interplay between cognitive and motivational processes in anger. The studies show that anger-induced approach motivation narrows people's percepetual and conceptual span of attention. This kind of 
research on the motivation-cognition interface will be a major research priority in years to come.

* [47] E . Fernandez, S.L . J ohnson, Anger in psychological disorders: Prevalence, presentation, etiology and prognostic implications, C lin. Psychol. R ev. 46 (2015) 124- 135. doi: 10.1016/j.cpr.2016.04.012.

A helpful discussion of the clinical-psychological relevance of anger management problems. The authors review how problems associated with anger regulation diverge and overlap between psychological disorders, and consider how transdiagnostic processes may be combined in more integrative therapies.

** [51] S.L . K oole, L. Veenstra, Does emotion regulation occur only inside people's heads? Toward a situated cognition analysis of emotion-regulatory dynamics, Psychol. Inq. 26 (2015) 61-68. doi:10.1080/1047840X .2015.964657.

This brief commentary relates findings on the situated nature of trait anger effects to the situated cognition literature and their broader implications for emotion regulation.

[1] C.A. A nderson, B.J. Bushman, Human aggression, A nnu. Rev. Psychol. 53 (2002) 2751.

[2] S. Pinker, The better angels of our nature: The decline of violence in history and its causes., Penguin, UK, 2011.

[3] J.L. Deffenbacher, Trait anger: Theory, findings, and implications, in: A dv. Personal. A ssessment., 1992: pp. 177-201.

[4] J.M. Owen, Transdiagnostic cognitive processes in high trait anger., Clin. Psychol. Rev. 31 (2011) 193-202. doi:10.1016/j.cpr.2010.10.003.

[5] B.M. Wilkowski, M.D. Robinson, The cognitive basis of trait anger and reactive 
aggression: an integrative analysis., Personal. Soc. Psychol. Rev. 12 (2008) 3-21. doi: $10.1177 / 1088868307309874$

[6] P.F. M erenda, Toward a four-factor theory of temperament and/or personality, J. Pers. A ssess. 51 (1987) 367-74. doi:10.1207/s15327752jpa5103_4.

[7] R.M. Stelmack, A. Stalikas, Galen and the humour theory of temperament, Pers. Individ. Dif. 12 (1991) 255-263. doi:10.1016/0191-8869(91)90111-N.

[8] C.D. Spielberger, Cross-cultural assessment of emotional states and personality traits, Eur. Psychol. 11 (2006) 297-303. doi:10.1027/1016-9040.11.4.297.

[9] B.M. Wilkowski, M.D. Robinson, The anatomy of anger: A n integrative cognitive model of trait anger and reactive aggression., J. Pers. 78 (2010) 9-38. doi:10.1111/j. 1467-6494.2009.00607.x.

[10] D. Spielberger, Charles, G. Jacobs, S. R ussell, R.S. Crane, A ssessment of anger: the state-trait anger scale., in: J.N. B utcher, D. Spiel berger, Charles (Eds.), A dv. Personal. A ssessment., Erlbaum A ssociates, Hillsdale, NJ , 1983.

[11] C.D. Spielberger, E.C. R eheiser, A ssessment of emotions: A nxiety, anger, depression, and curiosity, A ppl. Psychol. Heal. Well-B eing. 1 (2009) 271-302. doi:10.1111/j. 1758-0854.2009.01017.x.

[12] A.H. B uss, M. Perry, Personality processess and individual differences: The aggression questionnaire, J. Pers. Soc. Psychol. 63 (1992) 452-459.

[13] G. V. Caprara, V. Cinanni, G. D’Imperio, S. Passerini, P. Renzi, G. Travaglia, Indicators of impulsive aggression: Present status of research on irritability and emotional susceptibility scales, Pers. Individ. Dif. 6 (1985) 665-674. doi: 10.1016/0191-8869(85)90077-7.

[14] R. M artin, D. Watson, C.K. Wan, A three-factor model of trait anger: dimensions of 
affect, behavior, and cognition., J. Pers. 68 (2000) 869-897. doi:

10.1111/1467-6494.00119.

[15] J.L. Deffenbacher, A.N. Stephens, M .J.M. Sullman, Driving anger as a psychological construct: Twenty years of research using the Driving A nger Scale, Transp. Res. Part F. 42 (2016) 236-247. doi:10.1016/j.trf.2015.10.021.

[16] J. Booth, J.L. Ireland, S. M ann, S. Eslea, L. Holyoak, A nger expression and suppression in the workplace: Causes, characteristics and predictors., Int. J. Confl. M anag. (2016).

[17] S.M . Stith, D.B. Smith, C.E. Penn, D.B. Ward, D. Tritt, Intimate partner physical abuse perpetration and victimization risk factors: A meta-analytic review, 2004. doi:10.1016/ j.avb.2003.09.001.

[18] M.F. A rmey, H.T. Schatten, N. Haradhvala, I.W. Miller, Ecological momentary assessment (EM A) of depression-related phenomena, Curr. O pin. Psychol. 4 (2016) 21-25. doi:10.1016/j.copsyc.2015.01.002.Ecological.

[19] R.A. Sherman, J.F. Rauthmann, N.A. B rown, D.G. Serfass, A .B. Jones, The independent effects of personality and situations on real-time expressions of behavior and emotion, J. Pers. Soc. Psychol. 109 (2015) 872-888. doi:10.1037/pspp0000036.

[20] D. Edmondson, J.A. Shaffer, W.F. Chaplin, M .M . B urg, A .A. Stone, J.E. Schwartz, Trait anxiety and trait anger measured by ecological momentary assessment and their correspondence with traditional trait questionnaires, J. Res. Pers. 47 (2013) 843-852. doi:10.1016/j.immuni.2010.12.017.Two-stage.

[21] B.M. Wilkowski, M.D. Robinson, W. Troop-Gordon, How does cognitive control reduce anger and aggression? The role of conflict monitoring and forgiveness processes., J. Pers. Soc. Psychol. 98 (2010) 830-40. doi:10.1037/a0018962. 
[22] J. Suls, A nger and the Heart: Perspectives on cardiac risk, mechanisms and interventions, Prog. Cardiovasc. Dis. 55 (2013) 538-547. doi:10.1016/j.pcad. 2013.03.002.

[23] D. Herrero-Fernandez, Psychophysiological, subjective and behavioral differences between high and low anger drivers in a simulation task, Transp. Res. Part F Traffic Psychol. B ehav. 42 (2016) 365-375. doi:10.1016/j.trf.2015.12.015.

[24] J.L. Deffenbacher, E.R. Oetting, R.S. Lynch, C.D. M orris, The expression of anger and its consequences., B ehav. Res. Ther. 34 (1996) 575-90. http://www.ncbi.nlm.nih.gov/ pubmed/8826765.

[25] C.A. Quinn, D. Rollock, S.R. V rana, A test of Spielberger's state-trait theory of anger with adolescents: Five hypotheses., Emotion. 14 (2014) 74-84. doi:10.1037/a0034031.

[26] L. Berkowitz, A ggression: its causes, consequences, and control, M cGraw-Hill, N ew York, NY, 1993.

[27] N.R. Crick, K. a. Dodge, A review and reformulation of social information-processing mechanisms in children's social adjustment., Psychol. Bull. 115 (1994) 74-101. doi: 10.1037//0033-2909.115.1.74.

[28] L. Hung, R.A . B ryant, A utobiographical memory in the angry self, PL oS One. 11 (2016) 1-16. doi:10.1371/journal. pone.0151349.

[29] M. Takebe, F. Takahashi, H. Sato, A nger rumination as a risk factor for trait anger and anger-in: A longitudinal study, Pers. Individ. Dif. 101 (2016) 451-455. doi:10.1016/ j.paid.2016.06.038.

[30] A. Wenzel, C. Lystad, Interpretation biases in angry and anxious individuals., B ehav. Res. Ther. 43 (2005) 1045-54. doi:10.1016/j.brat.2004.02.009.

[31] K.G. Denny, M. Siemer, Trait aggression is related to anger-modulated deficits in 
response inhibition, J. Res. Pers. 46 (2012) 450-454. doi:10.1016/j.jrp.2012.04.001.

[32] K.N. Ochsner, J. a Silvers, J.T. B uhle, Functional imaging studies of emotion regulation: a synthetic review and evolving model of the cognitive control of emotion., A nn. N. Y. A cad. Sci. 1251 (2012) E1-24. doi:10.1111/j.1749-6632.2012.06751.x.

[33] S. Clifford, K. Lemery-Chalfant, H.H. Goldsmith, The unique and shared genetic and environmental contributions to fear, anger, and sadness in childhood, 86 (2015) 15831556. doi:10.1002/aur.1474.Replication.

[34] E. Vassos, D.A. Collier, S. Fazel, Systematic meta-analyses and field synopsis of genetic association studies of violence and aggression., M ol. Psychiatry. 19 (2014) 471-477. doi:10.1038/mp.2013.31.

[35] C.S. Carver, E. Harmon-J ones, A nger is an approach-related affect: evidence and implications., Psychol. Bull. 135 (2009) 183-204. doi:10.1037/a0013965.

[36] E. Harmon-J ones, C. Harmon-J ones, T.F. Price, What is approach motivation?, Emot. Rev. 5 (2013) 291-295. doi:10.1177/1754073913477509.

[37] P. a. Stevenson, J. Rillich, The decision to fight or flee - Insights into underlying mechanism in crickets, Front. N eurosci. 6 (2012) 1-12. doi:10.3389/fnins.2012.00118.

[38] E. Harmon-J ones, Clarifying the emotive functions of asymmetrical frontal cortical activity, Psychophysiology. 40 (2003) 838-848. doi:10.1111/1469-8986.00121.

[39] E. Harmon-J ones, Trait anger predicts relative left frontal cortical activation to angerinducing stimuli, Int. J. Psychophysiol. 66 (2007) 154-160. doi:10.1016/j.ijpsycho. 2007.03.020.

[40] M. Tops, M. Quirin, M .A.S. B oksom, S.L. K oole, Large-scale neural networks and the lateralization of motivation and emotion., Int. J. Psychophysiol. (2017).

[41] B. O. Y ildirim, J. Derksen, A review on the relationship between testosterone and life- 
course persistent antisocial behavior, Psychiatry Res. 200 (2012) 984-1010. doi: 10.1016/j.psychres.2012.07.044.

[42] M.D. Robinson, R.L. Boyd, M.R. Persich, Dispositional anger and the resolution of the approach-avoidance conflict., Emotion. (2016). doi:http://dx.doi.org/10.1037/ emo0000189.

[43] L. Veenstra, I.K . Schneider, B.J. Bushman, S.L. K oole, D rawn to danger: trait anger predicts automatic approach behaviour to angry faces., Cogn. Emot. (2016) 1-7. doi: 10.1080/02699931.2016.1150256.

[44] L. Veenstra, I.K. Schneider, B.J. Bushman, I. Domachowska, K. Dillon, S.L. K oole, Taming tempers: Avoidance motivation attenuates the association between trait anger and state anger/aggression, (n.d.).

[45] T.S. Braver, M.K. Krug, K.S. Chiew, W. Kool, J.A. Westbrook, N.J. Clement, R.A. A dcock, D.M. B arch, M .M. B otvinick, C.S. Carver, R. Cools, R. Custers, A. Dickinson, C.S. Dweck, A . Fischbach, P.M . Gollwitzer, T.M . Hess, D.M . Isaacowitz, M. M ather, L. Pessoa, G.R. Samanez-Larkin, L.H. Somerfille, M echanisms of motivation-cognition interaction: Challenges and opportunities, Cogn. A ffect. B ehav. Neurosci. 14 (2016) 443-472. doi:10.3758/s13415-014-0300-0.M echanisms.

[46] P.A. Gable, B.D. Poole, E. Harmon-J ones, A nger perceptually and conceptually narrows cognitive scope., J. Pers. Soc. Psychol. 109 (2015) 163-174. doi:10.1037/ a0039226.

[47] E. Fernandez, S.L. Johnson, A nger in psychological disorders: Prevalence, presentation, etiology and prognostic implications, Clin. Psychol. Rev. 46 (2015) 124135. doi:10.1016/j.cpr.2016.04.012.

[48] J.L. Deffenbacher, Cognitive-B ehavioral Conceptualization and Treatment of A nger, 
Cogn. B ehav. Pract. 18 (2011) 212-221. doi:10.1016/j.cbpra.2009.12.004.

[49] R. DiGiuseppe, R.C. Tafrate, A nger treatment for adults: A meta-analytic review, Clin. Psychol. Sci. Pract. 10 (2006) 70-84. doi:10.1093/clipsy.10.1.70.

[50] K. Howells, A. Day, Readiness for anger management: Clinical and theoretical issues, Clin. Psychol. Rev. 23 (2003) 319-337. http://ovidsp.ovid.com/ovidweb.cgi? $T=J S \& P A G E=r e f e r e n c e \& D=e m e d 6 \& N E W S=N \& A N=2003065394$.

[51] S.L. K oole, L. Veenstra, Does emotion regulation occur only inside people's heads? Toward a situated cognition analysis of emotion-regulatory dynamics, Psychol. Inq. 26 (2015) 61-68. doi:10.1080/1047840X .2015.964657.

[52] L. Veenstra, I.K. Schneider, S.L. K oole, The effect of motivational training on state anger and aggressive impulses among people with varying trait anger., (n.d.).

\section{References of I llustrative Material}

A Itmann, G. (n.d.). [online image] Retrieved from https://pixabay.com/nl/burnout-uitgeputalleen-eenzaamheid-384083/

D oran, B (2011). Deal with it [online image]. Retrieved from https://www.flickr.com/photos/ brandondoran/5953556828/in/faves-147375424@ N07/

H eart pathology Chagas disease [online image] (2007). Retrieved from https:// commons.wikimedia.org/wiki/File:Heart_pathology_Chagas_disease.JPG

M oralee, N. (2012). Don't hit me again .... . [online image] Retrieved from https:// www.flickr.com/photos/neilmoralee/8119371191/in/faves-147375424@ N07/

N ormand, A . (2008). The Bottle (45th/52) [online image]. Retrieved from https:// www.flickr.com/photos/alexnormand/3040359870

Vong, C. K. (2009). A nger management [online image]. Retrieved from https:// www.flickr.com/photos/kaichanvong/3351114426 


\section{Trait Anger}

\section{Basic Processes}
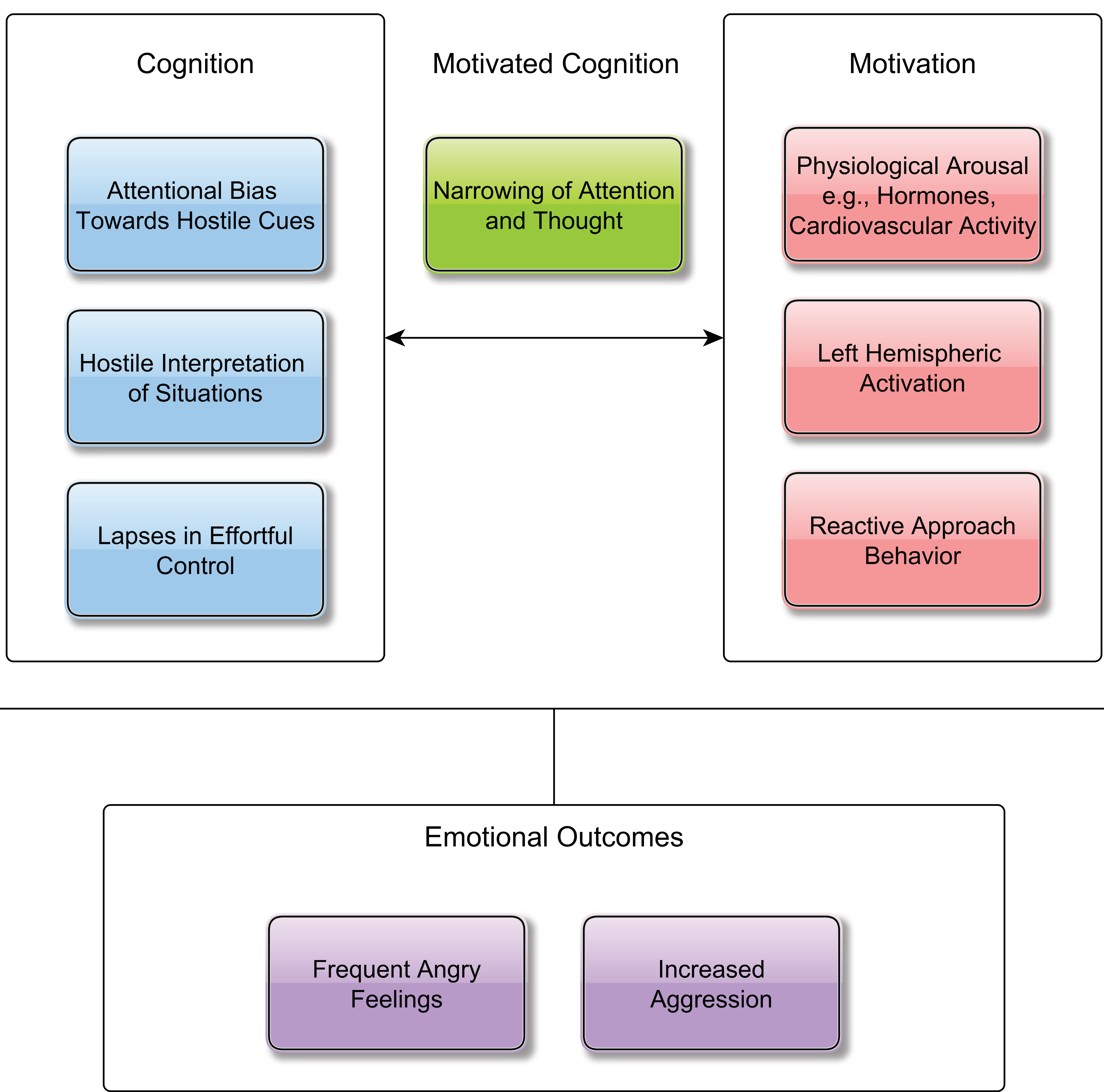

Social Problems

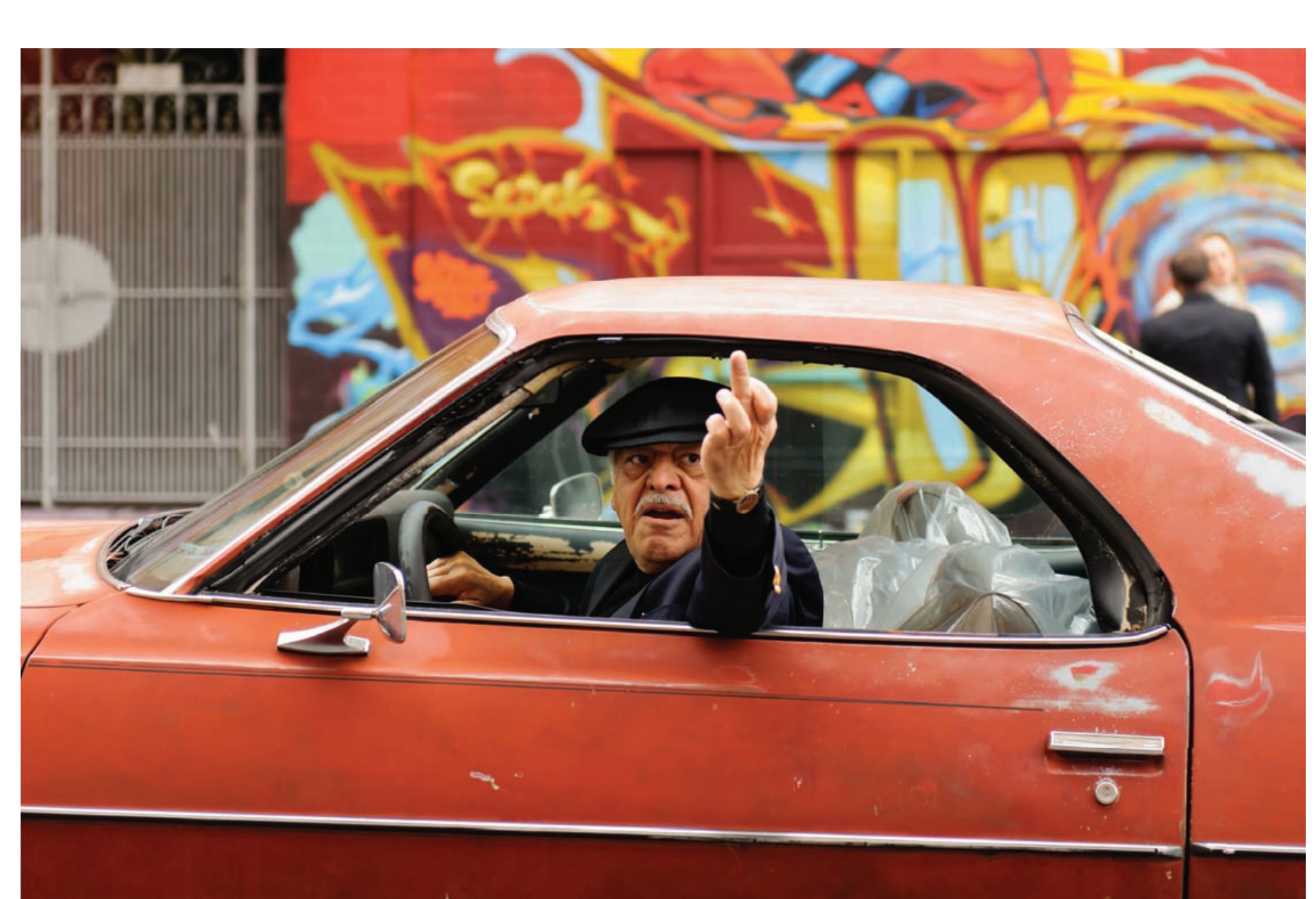

Road Rage

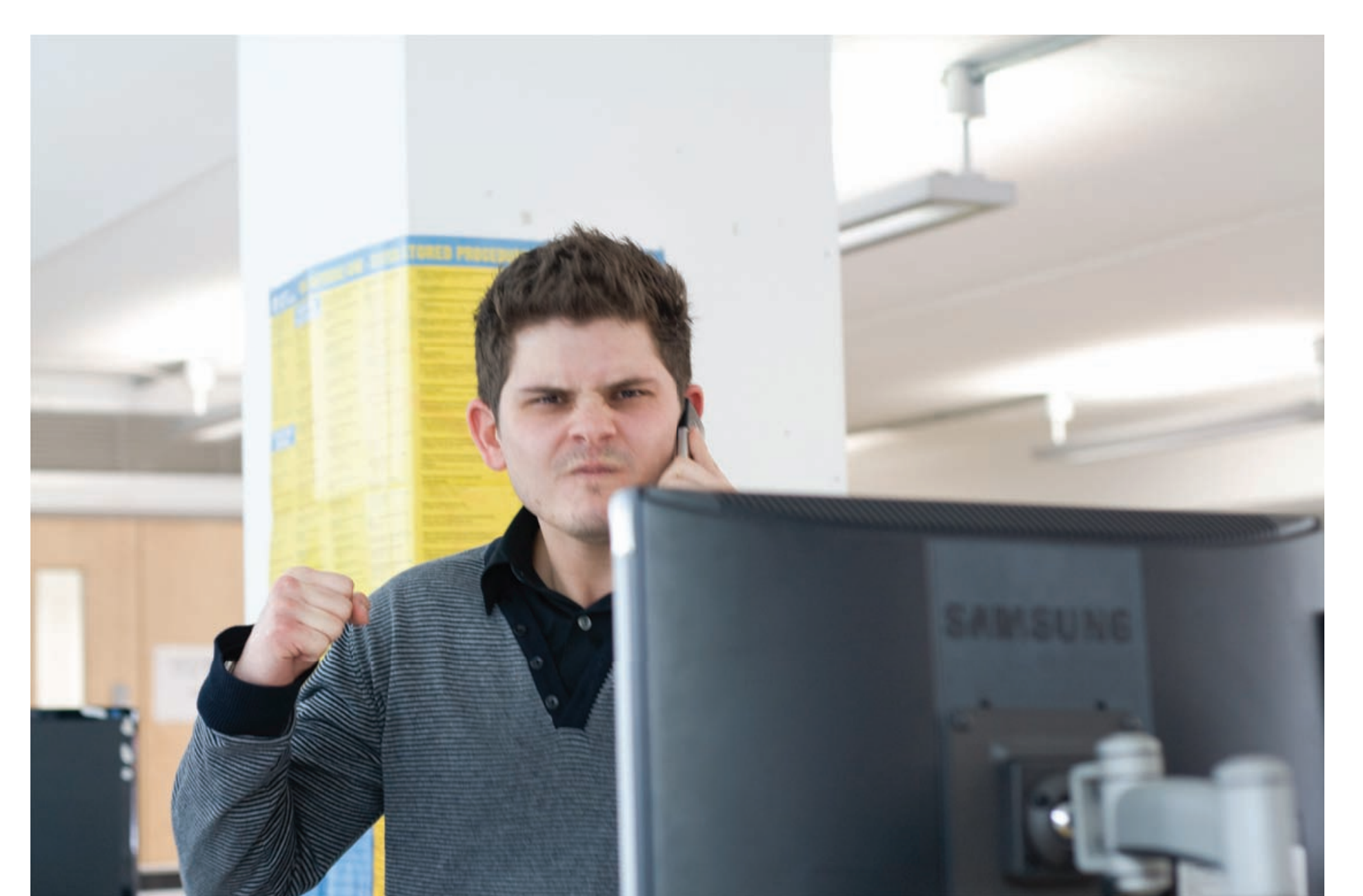

Work Aggression

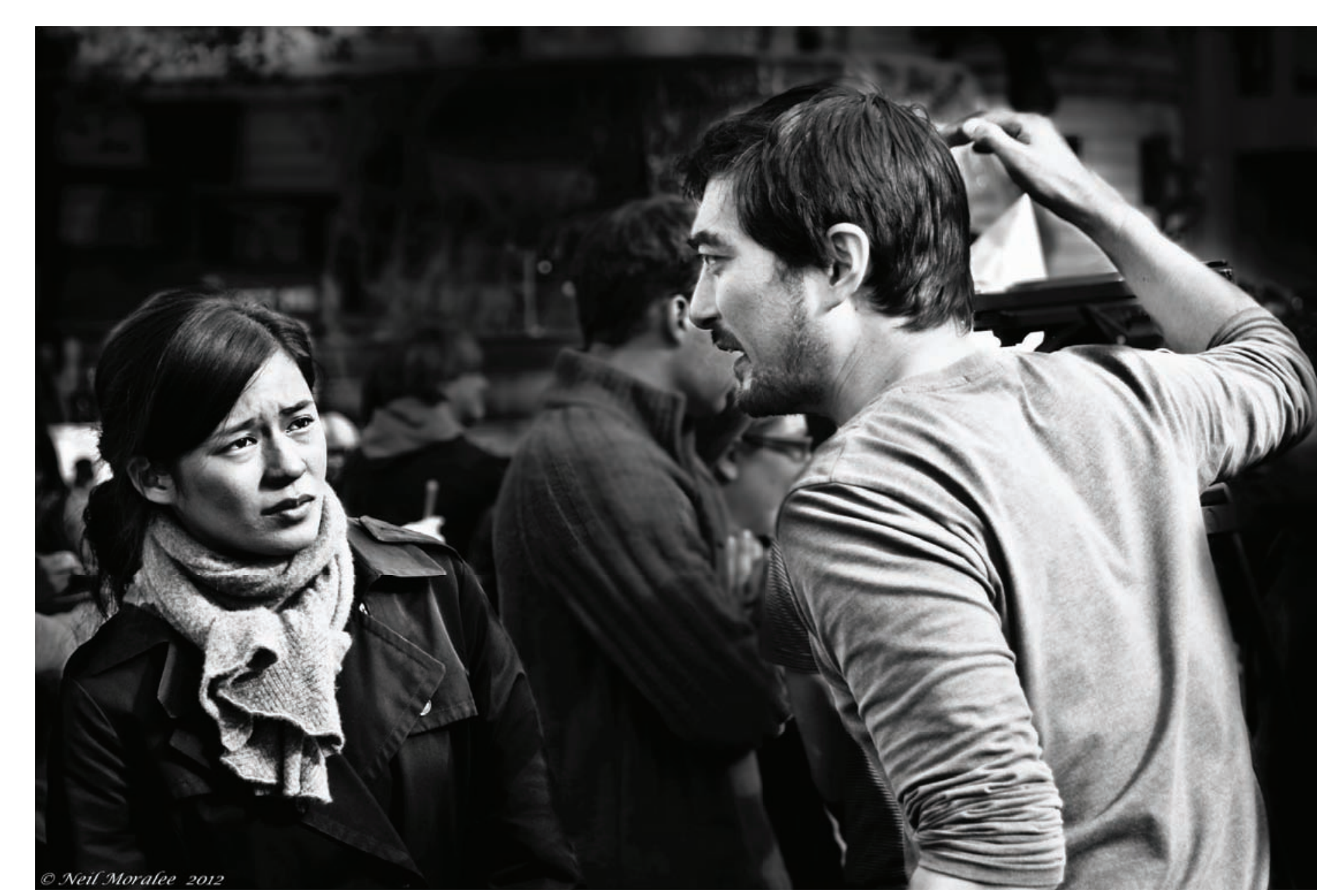

Domestic Violence
Clinical Problems

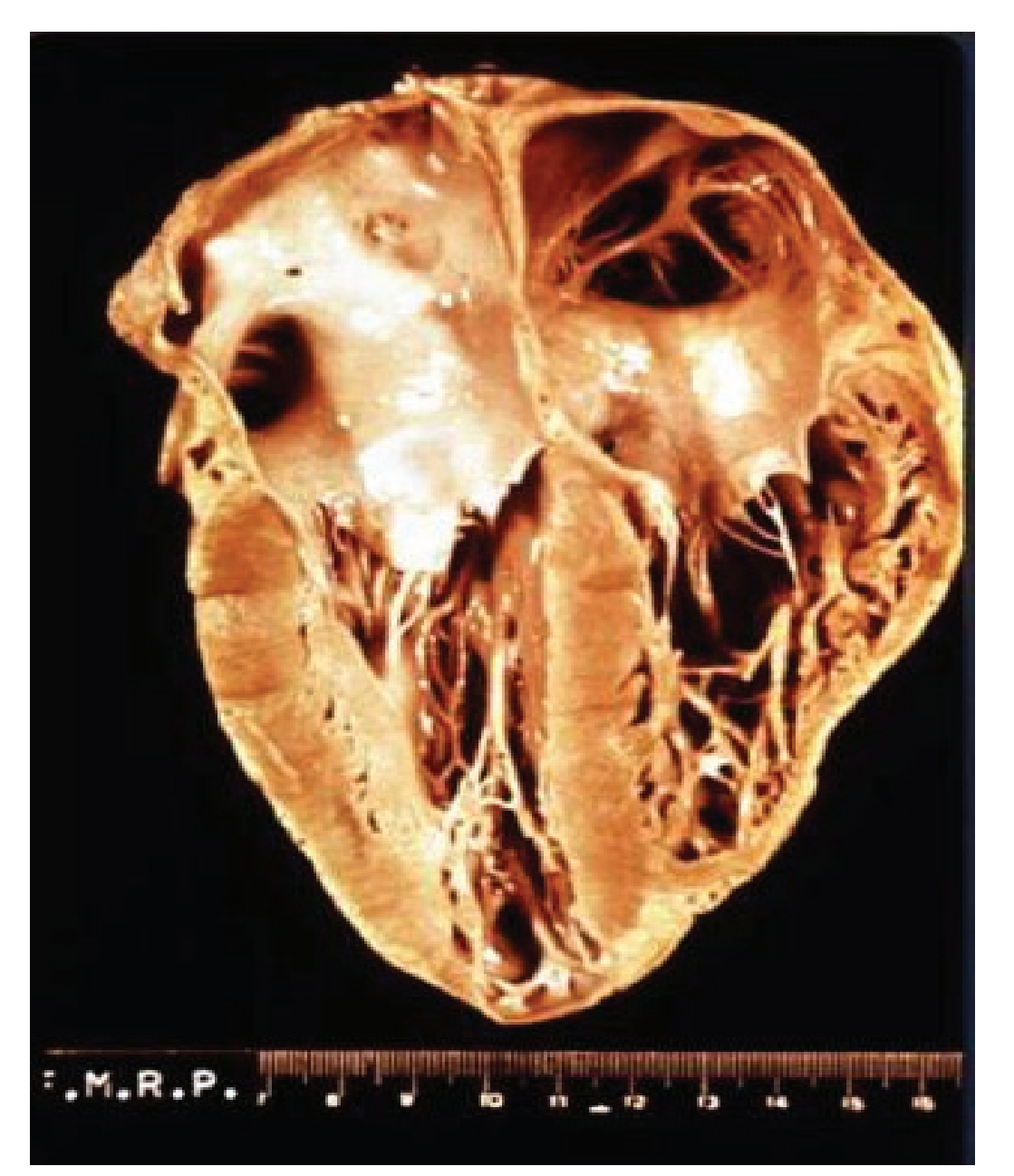

Cardiovascular Disease

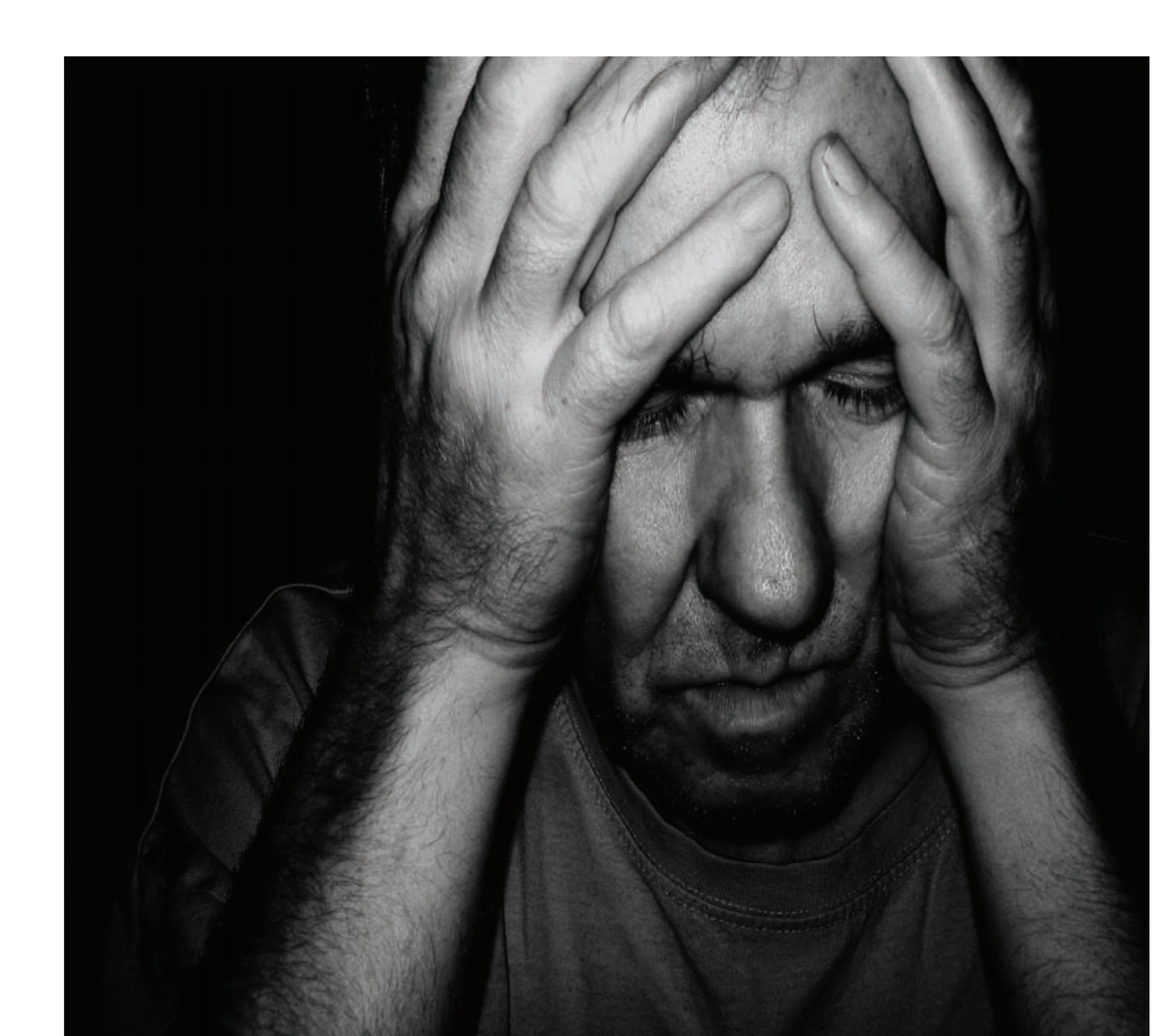

Psychological Disorders

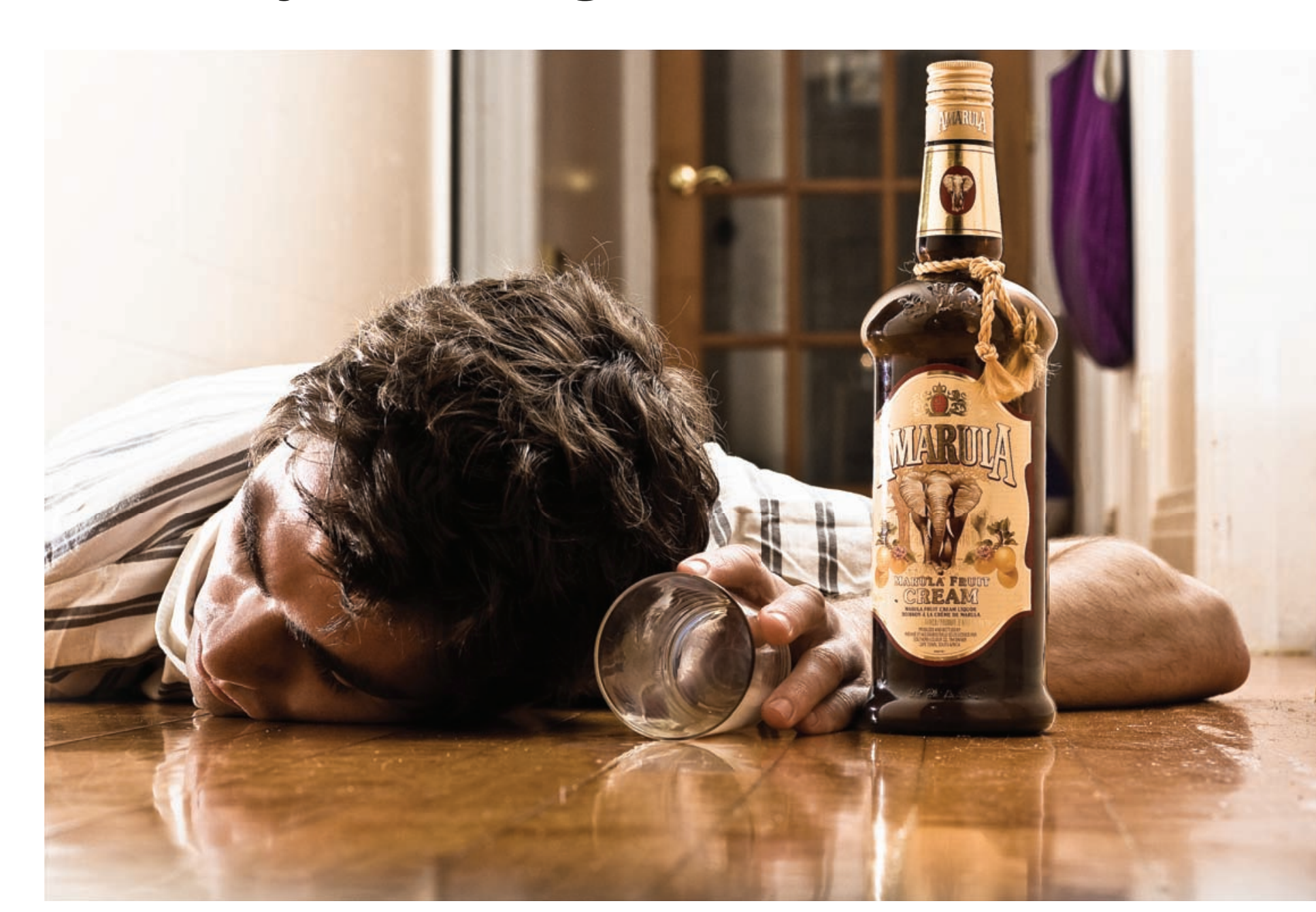

Alcohol Abuse 


\section{THE PSYCHOLOGY OF TRAIT ANGER}

Figure 1. The Psychology of Trait Anger.

The top level represents individual differences in trait anger. The second level depicts the basic cognitive and motivational processes that are associated with trait anger. The third level shows the emotional outcomes related to high trait anger. Finally, the lowest level illustrates the social and clinical problems related to high trait anger. 